\title{
Uptake of magnetic nanoparticles for adipose-derived stem cells with multiple passage numbers
}

\author{
Yan Yang ${ }^{1}$, Qiwei Wang ${ }^{1}$, Lina Song ${ }^{1}$, Xuan Liu $^{2}$, Peng Zhao ${ }^{1}$, Feimin Zhang ${ }^{3}$, Ning $\mathrm{Gu}^{1 *}$ and \\ Jianfei Sun ${ }^{1 *}$
}

\begin{abstract}
With the increasingly promising role of nanomaterials in tissue engineering and regenerative medicine, the interaction between stem cells and nanoparticles has become a critical focus. The entry of nanoparticles into cells has become a primary issue for effectively regulating the subsequent safety and performance of nanomaterials in vivo. Although the influence of nanomaterials on endocytosis has been extensively studied, reports on the influence of stem cells are rare. Moreover, the effect of nanomaterials on stem cells is also dependent upon the action mode. Unfortunately, the interaction between stem cells and assembled nanoparticles is often neglected. In this paper, we explore for the first time the uptake of $\gamma-\mathrm{Fe}_{2} \mathrm{O}_{3}$ nanoparticles by adipose-derived stem cells with different passage numbers. The results demonstrate that cellular viability decreases and cell senescence level increases with the extension of the passage number. We found the surface appearance of cellular membranes to become increasingly rough and uneven with increasing passage numbers. The iron content in the dissociative nanoparticles was also significantly reduced with increases in the passage number. However, we observed multiple-passaged stem cells cultured on assembled nanoparticles to have similarly low iron content levels. The mechanism may lie in the magnetic effect of $\gamma-\mathrm{Fe}_{2} \mathrm{O}_{3}$ nanoparticles resulting from the field-directed assembly. The results of this work will facilitate the understanding and translation of nanomaterials in the clinical application of stem cells.
\end{abstract}

Keywords: nanoparticles, assembly, cellular response, cell passage, uptake

\section{INTRODUCTION}

Stem cells are playing an increasingly important role in tissue engineering and regenerative medicine [1]. Stem cell-based therapy has shown great potential for the treatment of many conditions, such as neural lesions [2], immunological diseases [3] and bone defects [4]. However, in clinical practice, establishing the source of stem cells remains a challenge. These sources must be safe, biocompatible, and free from any ethical dispute. Mesenchymal stem cells (MSCs) are typically considered to be capable of differentiation into vascular endothelial cells [5], osteoblasts [6], chondrocytes [7], and adipocytes [8]. The sources of MSCs are diverse and those derived from adipose tissue have immune exemption characteristics [9] and the ability to inhibit activated lymphocyte proliferation in allografts [10]. Thus, the adipose-derived mesenchymal stem cells (ADSCs) are especially suitable for clinical availability and application [11]. Despite this, an important clinical issue is that the number of freshly obtained stem cells in vivo is often too small to meet practical demand. Thus, cellular passaging has become necessary before cells can be utilized for therapy. Because the self-renewal and pluripotency of stem cells are closely dependent upon the passage number, the influence of passage number on stem cells is worth exploring.

Recently, magnetic nanoparticles have shown an increasingly promising role in the construction of novel scaffolds that can impose local magnetic, thermal, and mechanic stimuli [12-14]. As such, tissue growth can be accelerated and some small molecules or cytokines can be released in a controlled way [15]. Therefore, the interaction between stem cells and nanoparticles becomes very critical for the biomedical application of nanomaterials, and the entry of nanoparticles into cells is a primary issue. For the cellular uptake of nanoparticles freely suspended

\footnotetext{
${ }^{1}$ State Key Laboratory of Bioelectronics, Jiangsu Key Laboratory of Biomaterials and Devices, School of Biological Science and Medical Engineering, Southeast University, Nanjing 210009, China

2 School of Medicine, Southeast University, Nanjing 210009, China

${ }^{3}$ Stomatological Hospital of Jiangsu Province, Nanjing 210029, China

"Corresponding authors (emails: sunzaghi@seu.edu.cn (Sun J); guning@seu.edu.cn (Gu N))
} 
in solution, researchers have reported transmembrane pathways to include membrane infiltration [16], phagocytosis [17], and pinocytosis [18]. Endocytosis can be further divided into macropinocytosis, clathrin-mediated endocytosis, caveolin-mediated endocytosis, and clathrin-/caveolin-independent endocytosis [19]. It is widely accepted that most nanoscaled objects are transported across the lipid bilayer through clathrin-mediated endocytosis [20-22], which is highly dependent upon the fluidity of the cell membrane [23]. Although the influence of nanomaterials has been extensively studied, the influence of stem cells, especially with respect to passaging, has rarely been reported. Moreover, cellular uptake should be explored not only with respect to dissociative nanoparticles but also those that are assembled. The latter are more important for transplanting stem cells into the body via a nanoparticle-modified scaffold. Whereas free-floating nanoparticles are often used as drugs and enter the body via veins, assembled nanoparticles can be integrated with implantable devices. Their administrative regulation differs such that assembled nanoparticles are more easily clinically translated. In addition, assembled nanoparticles can exhibit some novel collective properties that freefloating nanoparticles do not. Different aggregation states of magnetic nanoparticles have shown various effects on the fates of stem cells $[24,25]$. Therefore, the endocytosis of both free-floating and assembled nanoparticles are worthy of further research.

In this study, we investigated the uptake of $\gamma-\mathrm{Fe}_{2} \mathrm{O}_{3}$ nanoparticles by ADSCs with multiple passage numbers. In our experiments, we employed both free-floating nanoparticles in suspension and assembled nanoparticles on solid substrate. Because ADSCs are readily clinically available, they are often loaded on nanoparticle-modified scaffolds to repair bone tissue by implantation. In this case, the effect of the assembled nanoparticles on cells is most important. We measured the cell cycle, viability, proliferation, cellular senescence, intracellular iron content, and the expression level of several important proteins at various passages. Our data demonstrate that freefloating and assembled nanoparticles may have different pathways for entering cells. By increasing the passage number, we found the phagotrophic capability of the cells to be significantly reduced. Assembly can effectively inhibit the cellular uptake of nanoparticles, which may be due to the non-covalent magnetic couplings between individual units. Our results indicate that the entry of dissociative nanoparticles into stem cells is greatly dependent on the passage number, whereas that of assembled nanoparticles is independent of passage number. Phagocy- tosis can be inhibited by the non-covalent interaction among nanoparticles such that there will be only tiny amounts of nanoparticles entering the stem cells.

\section{EXPERIMENTAL SECTION}

\author{
Synthesis, assembly, and characterization of bare $\gamma-\mathrm{Fe}_{2} \mathrm{O}_{3}$ \\ nanoparticles
}

Synthesis of bare $\gamma-\mathrm{Fe}_{2} \mathrm{O}_{3}$ nanoparticles

We slowly added $25 \%(w / w) \mathrm{N}\left(\mathrm{CH}_{3}\right)_{4} \mathrm{OH}$ to a mixture of $\mathrm{Fe}^{2+}$ and $\mathrm{Fe}^{3+}$ (molar ratio is 1:2) until reaching a $\mathrm{pH}$ value of 13. This reaction was allowed to continue for $1 \mathrm{~h}$ to obtain black colloidal nanoparticles $\left(\mathrm{Fe}_{3} \mathrm{O}_{4}\right)$. Then, we pumped air into the reaction system in a $95^{\circ} \mathrm{C}$ water bath after adjusting the $\mathrm{pH}$ value to 3 . Finally, we maintained this reaction system for $3 \mathrm{~h}$ to oxidize the $\mathrm{Fe}_{3} \mathrm{O}_{4}$ nanoparticles into $\gamma-\mathrm{Fe}_{2} \mathrm{O}_{3}$ nanoparticles. Vigorous stirring was employed throughout the whole reaction.

\section{Assembly of $\gamma-\mathrm{Fe}_{2} \mathrm{O}_{3}$ nanoparticles}

We purified the synthesized nanoparticles several times by centrifugal and magnetic separation until reaching a $\mathrm{pH}$ of 7 . Then, we placed a drop of $60-\mu \mathrm{L}$ colloidal suspension onto a rounded glass plate $(d=15 \mathrm{~mm})$, which had been pre-cleaned using a boiling mixture of $\mathrm{H}_{2} \mathrm{O}_{2}$ / $\mathrm{H}_{2} \mathrm{SO}_{4}$ (volume ratio: 1:3). We generated a magnetic field using a "C"-shaped solenoid in which the field strength can be changed by tuning the excitation current. The cross section was $4 \mathrm{~cm} \times 4 \mathrm{~cm}$ and the gap was $2 \mathrm{~cm}$. We placed the glass plate in the middle of the gap. During the assembly, the field was parallel to the glass plate and remained there until the colloidal suspension was thoroughly dried. By iterative experimentation, we found that a $120-\mathrm{mT}$ field intensity yielded the best nanoparticle pattern formation, so we fabricated all the assemblies in our experiments in the presence of a 120 -mT magnetostatic field.

We characterized the morphology of the nanoparticles by transmission electron microscopy (TEM) (832.20B, Gatan, American), the hydrodynamic diameter and $\zeta$ potential of the bare $\gamma-\mathrm{Fe}_{2} \mathrm{O}_{3}$ nanoparticles using a Malvern Zetasizer Nano (Malvern Instruments Ltd., Worcestershire, UK), and the morphology of the nanogranular assemblies by scanning electron microscopy (SEM) (Ultra Plus, Zeiss, Germany).

\section{Cell culture of SD-ADSCs cells}

We purchased commercial SD-ADSC cells (RASMD01001, Cyagen, American) and cultured the cells with an 
SD-ADSC complete medium containing $10 \%$ fetal bovine serum (FBS), 1\% penicillin-striptomyxin, and 1\% glutamine (RASMD-90011, Cyagen, American) in a humidified atmosphere with $5 \% \mathrm{CO}_{2}$ at $37^{\circ} \mathrm{C}$. We changed the culturing medium every three days. When the cells reached $80 \%$ confluence, they required one passaging. We harvested the cells using a $0.25 \%(w / v)$ trypsin-ethylene diamine tetra-acetic acid solution.

\section{Cell viability}

We used flow cytometry to measure the viability of the cells without nanoparticle treatment. We seeded the ADSCs at multiple passage numbers in bare 24-well plates $\left(5 \times 10^{4}\right.$ cells per well) for $24 \mathrm{~h}$. Then, we incubated the cells with RNase A $\left(100 \mathrm{mg} \mathrm{mL}^{-1}\right)$ at $37^{\circ} \mathrm{C}$ for $30 \mathrm{~min}$, followed by staining with propidium iodide (PI) $\left(40 \mathrm{mg} \mathrm{mL}^{-1}\right)$ at $4^{\circ} \mathrm{C}$ for $30 \mathrm{~min}$ in a dark environment. After staining, we immediately measured the samples with a FACSCalibur flow cytometer (Becton-Dickinson) and analyzed the data using FlowJo software (Tree Star, Ashland, OR, USA).

We measured the viability of cells treated by either dissociative or assembled nanoparticles using a Cell Counting Kit-8 (CCK-8). We seeded the cells of multiple passage numbers in 24 -well microtiter plates $\left(0.5 \times 10^{4}\right.$ cells $/ 200 \mu \mathrm{L}$ culture medium/well) for different experimental groups. For cells cultured on nanoparticle assemblies, direct measurement of viability was not possible. After seeding the cells on the assemblies of nanoparticles in 24-well plates for $24 \mathrm{~h}$ incubation, we washed the cells twice with phosphate buffer solution (PBS). Then, we added CCK-8 reagent to each well and co-incubated it with the cells for $1 \mathrm{~h}$ at $37^{\circ} \mathrm{C}$. Next, we suctioned the reaction liquid onto the bare culture plate to reduce the impact of the substrate in the detection process in which bubbles must be avoided. Finally, we determined the absorbance at two wavelengths $(450 \mathrm{~nm}$ for the soluble dye and $650 \mathrm{~nm}$ for the viable cells) using a microplate reader (SpectraMax M5, Molecular Devices, Sunnyvale, CA, USA). We then calculated the cellular viability by the following formula:

$$
\text { Viability }(\%)=\left[\left(\mathrm{OD}_{\mathrm{i}}-\mathrm{OD}_{\text {blank }}\right) /\left(\mathrm{OD}_{\text {cell }}-\mathrm{OD}_{\text {blank }}\right)\right] \times 100 \% \text {, }
$$

where $\mathrm{OD}_{\mathrm{i}}$ is the $\mathrm{OD}$ value of each well, $\mathrm{OD}_{\text {blank }}$ is the $\mathrm{OD}$ value of the well with the culturing medium but without the cells, and $\mathrm{OD}_{\text {cell }}$ is the OD value of the well with cells cultured in the absence of nanomaterials.

\section{Detection of senescence}

We cultured the ADSCs of multiple passage numbers on a commerical 24-well culturing plate without adding any nanoparticles, with the addition of dissociative $\gamma-\mathrm{Fe}_{2} \mathrm{O}_{3}$ nanoparticles, and on a glass surface with stripe-like assemblies of $\gamma-\mathrm{Fe}_{2} \mathrm{O}_{3}$ nanoparticles, respectively, for $24 \mathrm{~h}$. We fabricated the assemblies on a rounded glass plate that fit precisely into the well of the commercial 24-well culturing plate. The cell concentration was $2 \times 10^{4}$ cells/well. We then fixed and stained the cells to detect SA $\beta$-gal activity using a Senescence $\beta$-Galactosidase Staining Kit (Beyotime Institute of Biotechnology, China). After $37^{\circ} \mathrm{C}$ incubation overnight, we stained a percentage of SA $\beta$-gal positive cells blue.

\section{Morphological characterization of cells}

We observed the cellular morphology by fluorescent microscopy and SEM.

For fluorescent staining and observation, we washed the ADSCs of multiple passage numbers with PBS and fixed them in $3.7 \%$ formaldehyde for $15 \mathrm{~min}$ at room temperature $\left(25^{\circ} \mathrm{C}\right)$. We then washed the fixed cells with PBS and blocked them with a solution of $1 \%$ bovine serum albumin (BSA) and $0.1 \%$ Triton X-100 in PBS for 5 min at room temperature, after which we washed out the redundant reagents with PBS. Then, we incubated the cells with rhodamine-phalloidin (Keygen) for $20 \mathrm{~min}$. Next, we washed the cells with PBS and incubated them with Hoechst 33258 (Keygen) for 5 min to stain the F-actin. We then observed the stained ADSCs using a confocal laser scanning microscope system (Olympus, Japan).

For SEM imaging, we cultured the cells at multiple passage numbers on cell slides at an initial density of $2 \times$ $10^{4}$ cells/well for $24 \mathrm{~h}$. After washing for three times with PBS, we fixed the cells with $2.5 \%$ glutaraldehyde in PBS and stored them at $4^{\circ} \mathrm{C}$ overnight. Prior to SEM imaging, we dehydrated the ADSCs in a series of ethanol concentrations $(30 \%, 50 \%, 70 \%, 80 \%, 90 \%, 95 \%$, and 100\%). Finally, we maintained the dehydrated ADSCs in a desiccator for overnight air drying. We performed SEM imaging on an SEM system (Ultra Plus, Zeiss, Germany).

\section{Flow cytometry identification of cells}

We seeded cells at the $12^{\text {th }}$ passage number in a 6-well plate $\left(2 \times 10^{5}\right.$ cells/well $)$ for $24 \mathrm{~h}$. Then, we digested the cells and washed them three times with PBS. We then blocked the washed cells with a solution of 3\% BSA for $30 \mathrm{~min}$ and mixed the cells $\left(10^{6}\right.$ cells $\left./ 100 \mu \mathrm{L}\right)$ with fluorescent-labeled antibodies $\left(0.25 \mu \mathrm{g} \mathrm{L}^{-1}\right)$ for $1 \mathrm{~h}$ at room temperature. We measured the blank cells (control) and antibody-labeled cells by flow cytometry (BD FACSCalibur, America) and analyzed the data using FlowJo soft- 
ware.

\section{Uptake of $\gamma-\mathrm{Fe}_{2} \mathrm{O}_{3}$ nanoparticles (ICP-OES)}

We cultured the cells of multiple passage numbers on a commercial culturing plate without the addition of nanoparticles (control), with the addition of dissociative $\gamma$ $\mathrm{Fe}_{2} \mathrm{O}_{3}$ nanoparticles $\left(\gamma-\mathrm{Fe}_{2} \mathrm{O}_{3}\right)$, and on a glass surface with stripe-like assemblies of $\gamma-\mathrm{Fe}_{2} \mathrm{O}_{3}$ nanoparticles $(120 \mathrm{mT})$, respectively, with a $5 \times 10^{4}$ cells/well concentration. After $24 \mathrm{~h}$ of culturing, we digested the cells and washed them three times with PBS. Finally, we dissolved the cells with $64 \%$ nitric acid after counting. We determined the $\mathrm{Fe}$ concentration by inductively coupled plasma optical emission spectrometry (ICP-OES).

\section{Intracellular localization of $\gamma-\mathrm{Fe}_{2} \mathrm{O}_{3}$ nanoparticles (TEM imaging)}

After $24 \mathrm{~h}$ incubation, we digested the cells and washed them three times with PBS. Then, we fixed the cells with $2.5 \%$ glutaraldehyde in PBS and stored them at $4^{\circ} \mathrm{C}$. We dehyrated the cell pellets with ethanol in a series of concentrations $(20 \%, 30 \%, 40 \%, 50 \%, 60 \%, 70 \%$, and $90 \%)$. Then, we treated the cell pellets with $2 \%$ uranyl acetate in $95 \%$ ethanol (en bloc stain) for $1 \mathrm{~h}$ and further dehydrated them with $100 \%$ ethanol for $1 \mathrm{~h}$. Lastly, we treated the cell pellets with propylene oxide twice (15 min each time), followed by treatment with a mixture of propylene oxide and araldite resin (volume ratio 1:1). Subsequently, we embedded the cells in araldite resin at $60^{\circ} \mathrm{C}$ for $48 \mathrm{~h}$ to produce ultrathin sections with a microtome. We then mounted these slices on copper grids and stained them with $1 \%$ aqueous uranyl acetate and $0.2 \%$ lead citrate for imaging by TEM (JEM-2000EX, JEOL) at $80 \mathrm{kV}$ acceleration voltage.

\section{Statistical analysis}

To perform our statistical analysis of the experimental data, we used SPSS software (version 19.0). We obtained all of the values from more than three independent experiments and express the figure data in mean $\pm \mathrm{SD}$ format, where the mean is the averaged value of the data and SD is the standard deviation. The error bar in the figures denote the standard deviations. We subjected the results to one-way analysis of variance using Duncan's test to analyze the difference between the experimental groups. We considered a statistical difference of less than 0.05 to be significant.

\section{RESULTS AND DISCUSSION}

The synthesized $\gamma-\mathrm{Fe}_{2} \mathrm{O}_{3}$ nanoparticles were bare and stabilized by surface hydroxylation. These nanoparticles were about $10 \mathrm{~nm}$ (Fig. 1a) in size and their hydrodynamic diameters were about $82.65 \mathrm{~nm}$ (Supplementary information, Fig. S1a). The nanoparticles were negatively charged with a $\zeta$ potential of $-14.4 \mathrm{mV}$ (Fig. S1b). To obtain good pattern formation by the magnetic field-directed assembly, we magnetically separated the colloidal suspension for purification. After magnetic separation, the nanoparticles formed small clusters (Fig. 1b) and their hydrodynamic size changed to about $161.5 \mathrm{~nm}$ (Fig. S1a). We used this sample for both the magnetic field-directed assembly and in the cellular experiments with the dissociative nanoparticles. Fig. 1c shows the stripe-like pattern of the $\gamma-\mathrm{Fe}_{2} \mathrm{O}_{3}$ nanoparticles that formed in the presence of an external magnetostatic field (Fig. 1d shows the local magnification of Fig. 1c). Here the field intensity was $120 \mathrm{mT}$, which we had determined to be the optimal value after repeated experimentation. In our experiments, we fabricated all the assemblies of magnetic nanoparticles at this field intensity.

Then, we cultured the ADSCs of multiple passage numbers on the commercial culturing plate (control), the commercial culturing plate with the addition of the dissociative $\gamma-\mathrm{Fe}_{2} \mathrm{O}_{3}$ nanoparticles, and the glass surface with the stripe-like assemblies, respectively, for $24 \mathrm{~h}$ (Fig. 1e, f). Next, we measured the cellular senescence level by SA $\beta$ gal staining. SA $\beta$-gal positive cells will be blue in optical images. Fig. 2a shows optical photos of the staining results. To quantitatively compare the senescence level with the passage number, we developed an image processing method for calculating the percentages of SA $\beta$-gal positive areas (Fig. 2b). A detailed description of this method can be found in the Supplementary information (Fig. S2). As we can see in Fig. 2b, the senescence level of cells increased with additional cell passage numbers in all three cases. However, the cells cultured on the nanoparticle assemblies aged faster whereas the dissociative $\gamma-\mathrm{Fe}_{2} \mathrm{O}_{3}$ nanoparticles seemed to slightly inhibit senescence. Here, we note that the absolute senescence values of the three samples have little meaning because the substrate for the assemblies was bare glass rather than a commercial culturing plate. The biocompatibility of the bare glass was obviously worse than that of the commercial culturing plate. However, this indicates that the stem cell performance may be dependent on the assembly state of the nanomaterials during application.

We performed flow cytometry in our analysis of the cellular cycle of different-passaged ADSCs after 24-h culturing on commercial plates without the addition of nanoparticles. We used a combination of the S and G2/M 
a

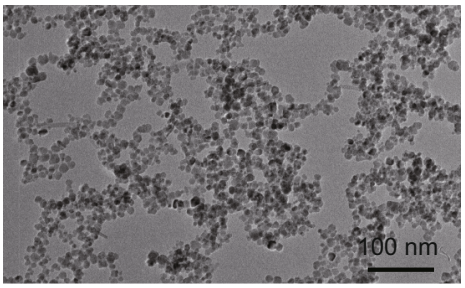

c

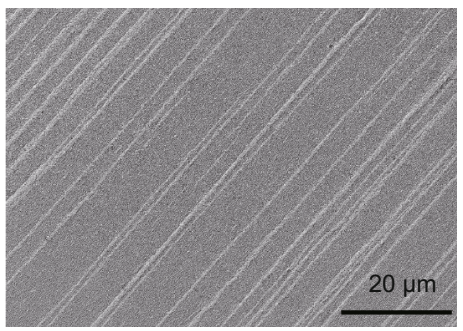

e

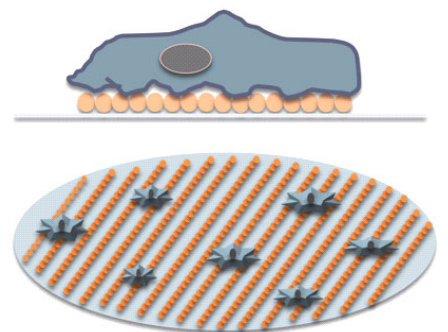

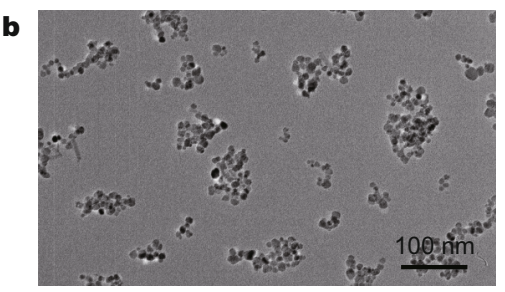

d

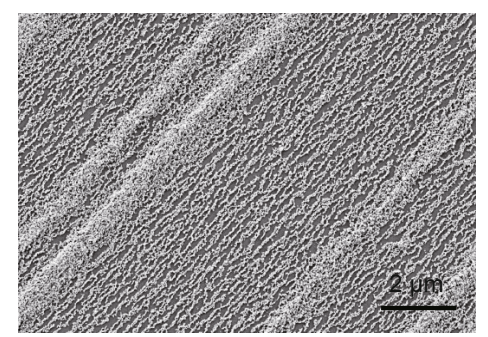

f

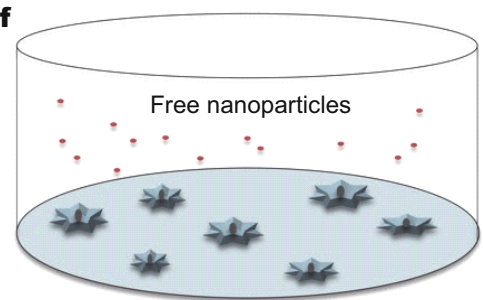

Figure 1 Characterization of nanoparticles and assemblies. (a) TEM image of $\gamma$ - $\mathrm{Fe}_{2} \mathrm{O}_{3}$ nanoparticles before magnetic separation. (b) TEM image of $\gamma$ $\mathrm{Fe}_{2} \mathrm{O}_{3}$ nanoparticles after magnetic separation. (c) SEM image of the assemblies. (d) Local magnification of (c). (e) Schematic illustration of SD-ADSCs cultured on the surface of stripe-like assemblies. (f) Schematic illustration of SD-ADSCs treated with dissociative $\gamma$-Fe $\mathrm{O}_{3}$ nanoparticles.

phases to describe the viability of different-passaged cells. We can see that the cell viability decreased with additional passage numbers, especially after the sixth-passaged cells (Fig. 3a). Fig. 3b-d show morphological images of the multiple-passaged ADSCs characterized by optical microscopy, fluorescent microscopy, and SEM, respectively. The third-passaged cells showed a typical spindle-like morphology but with an increase in the passage number, the cells widened and flattened, becoming more like polygons. The cytoskeleton staining results show that the extension of the pseudopodium and microfilament became more irregular. From the SEM images, we can also see that the cellular surface became increasingly rough. Some hollow microstructures emerged on the cellular surfaces after the third passage. This indicates that the permeability and fluidity of the cytomembrane was greatly altered with the increase of passage numbers. Here, we note that although there were significant changes occurring in the cellular morphology, even the 12thpassaged ADSCs were still MSCs. We employed the positive marker CD29 and the negative marker CD11b to identify the 12th-passaged ADSCs [26]. We show the flow cytometry results in the Supplementary information (Fig. S3), where the fluorescent peaks of CD29 and CD11b are in identical locations compared with those of the control. We performed a CCK8 assay to measure the viability of different-passaged ADSCs cultured in the presence of dissociative $\gamma-\mathrm{Fe}_{2} \mathrm{O}_{3}$ nanoparticles and on the surface of the stripe-like assemblies of $\gamma-\mathrm{Fe}_{2} \mathrm{O}_{3}$ nanoparticles. The results show a similar trend with that of the cells in the absence of nanoparticles (Fig. 3e). We also found that the dissociative $\gamma-\mathrm{Fe}_{2} \mathrm{O}_{3}$ nanoparticles seemed capable of enhancing cellular viability. The viability of cells obviously declined more slowly with the increase of passage numbers in the presence of dissociative $\gamma-\mathrm{Fe}_{2} \mathrm{O}_{3}$ nanoparticles. Here, we considered the nanoparticles to have little effect on the self-renewal and differentiation of ADSCs because we had conducted all our experiments after just $24 \mathrm{~h}$ coculturing. However, typically, it takes at least two weeks for ADSCs to differentiate. So, we consider $24 \mathrm{~h}$ to be too short a time for nanoparticles to renew or differentiate ADSCs. In addition, stem cells form colonies prior to 


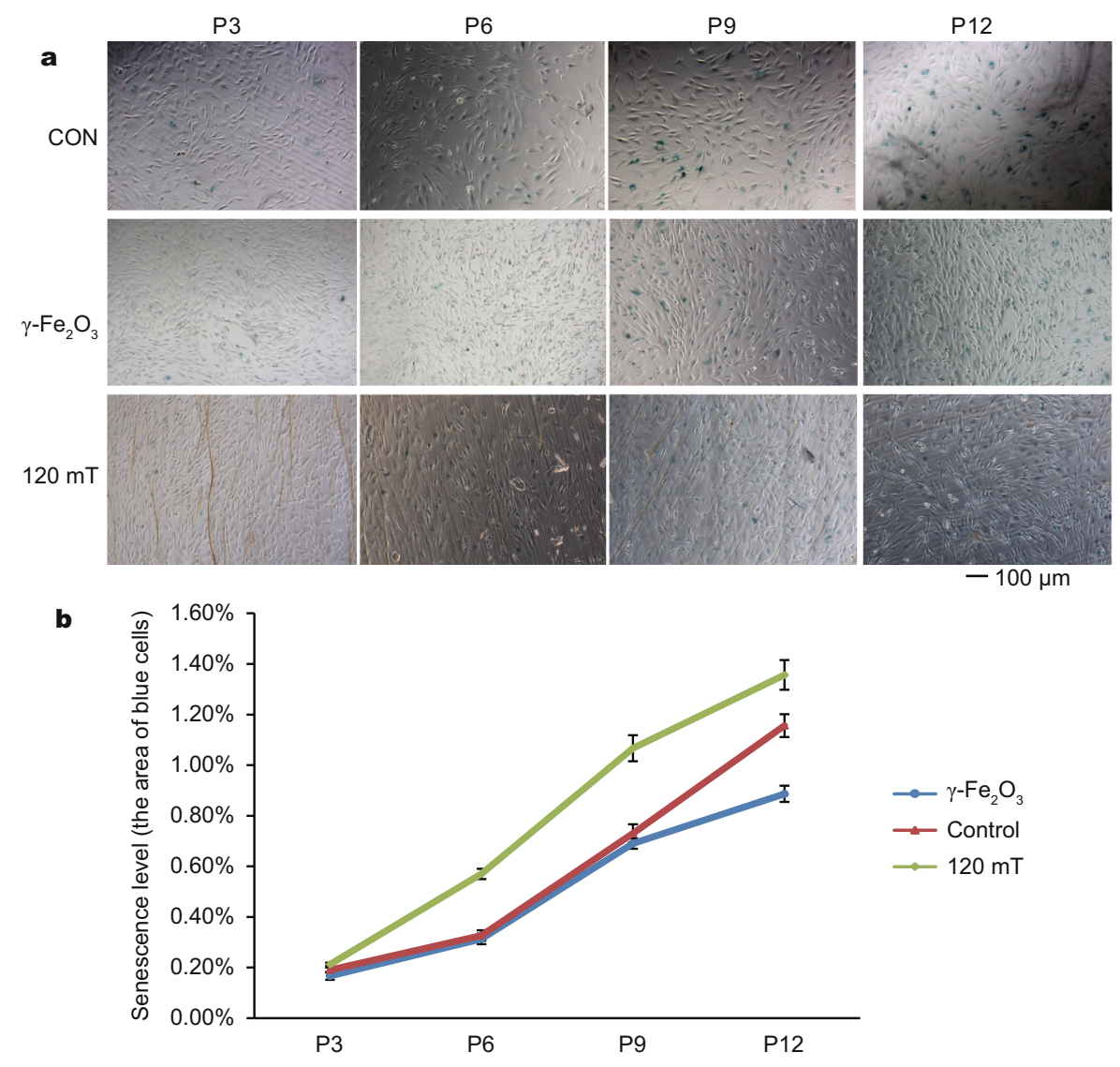

Figure 2 Senescence measurements for different-passaged ADSCs using the $\beta$-Galactosidase Staining Kit ( $\beta$-Galactosidase positive cells are blue). (a) Staining images for cells cultured on commercial culturing plate $(\mathrm{CON})$, treated by dissociative $\gamma$ - $\mathrm{Fe}_{2} \mathrm{O}_{3}$ nanoparticles $\left(\gamma\right.$-Fe $\left.\mathrm{O}_{3}\right)$, and cultured on the stripe-like assemblies $(120 \mathrm{mT})$. (b) Percentage of $\beta$-galactosidase positive area (blue area of (a)) calculated by our image processing method.

differentiation. However, from the morphological images of cells during our experiments, we can see that the ADSCs remained in the discrete state. This also confirms that the stem cells were prevented from differentiating.

We quantitatively measured the cellular uptake of the magnetic nanoparticles by ICP-OES after $24 \mathrm{~h}$ of culturing, the results of which are shown in Fig. 4a. For the dissociative nanoparticles, we found the Fe content inside the cells to be significantly reduced with an increase in the passage number. However, multiple-passaged cells cultured on the assemblies of nanoparticles showed little difference. Moreover, the internal Fe content of differentpassaged cells cultured on the assemblies was much less than that treated by the dissociative nanoparticles. This indicates that the field-directed assembly effectively inhibited the entry of nanoparticles into cells, which means better security in vivo [27]. Our microscopic observations also confirm this point (Fig. $4 \mathrm{~b}-\mathrm{e}$ ). We can see that the nanoparticles located in the endosomes in both the dis- sociative nanoparticles and the assemblies. However, the $\gamma-\mathrm{Fe}_{2} \mathrm{O}_{3}$ nanoparticles were in isotropic clusters in the cells treated with dissociative nanoparticles whereas the $\gamma$ $\mathrm{Fe}_{2} \mathrm{O}_{3}$ nanoparticles formed needle-like aggregates in the cells cultured on the assemblies. This reveals that the inhibition of the cellular uptake of nanoparticles possibly resulted from the field-induced aggregation of the magnetic nanoparticles. Due to the weak interaction between the elemental units, the entry of nanoparticles into the cells must demand more energy, which makes it more difficult for the cells to endocytose the nanoparticles [28]. Here, we note that the intracellular $\gamma-\mathrm{Fe}_{2} \mathrm{O}_{3}$ nanoparticles showed a needle-like aggregation in the cells cultured on magnetic field-directed assemblies. One possibility is that the assembled nanoparticles entered into the cells in the shape of small chains because the endocytosis could not break up the assembled nanoparticles into dissociative units. The other possibility is that the cellular uptake of nanoparticles occurred in the form of individual units 

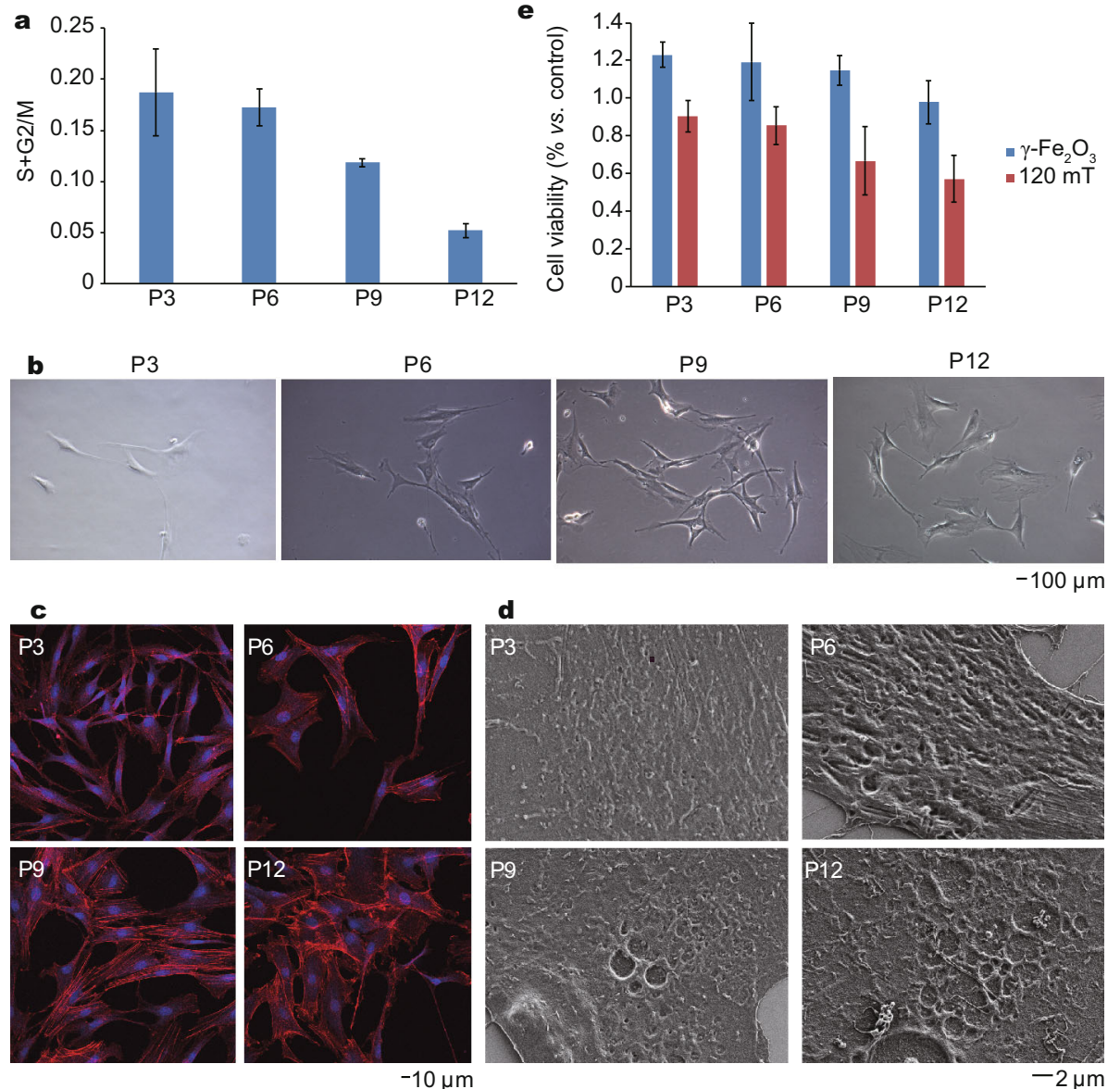

Figure 3 Characterization of different-passaged ADSCs. (a) Cell cycle measurement of different-passaged ADSCs without treatment of nanoparticles. (b) Morphological images of multiple-passaged ADSCs without treatment of nanoparticles characterized by bright field optical microscopy. (c) Morphological images of multiple-passaged ADSCs without treatment of nanoparticles characterized by fluorescent microscopy. (d) Morphological images of multiple-passaged ADSCs without treatment of nanoparticles characterized by SEM. (e) Viability measurements using CCK-8 assay for different-passaged ADSCs cultured on commercial culturing plate (control), treated by dissociative $\gamma-\mathrm{Fe}_{2} \mathrm{O}_{3}$ nanoparticles $\left(\gamma\right.$ - $\left.\mathrm{Fe}_{2} \mathrm{O}_{3}\right)$. and cultured on the stripe-like assemblies $(120 \mathrm{mT})$.

because particles anisotropic in shape could not easily enter into the cells due to the severe deformation of the cellular membrane. However, the magnetic nanoparticles may be assembled into small chains again during intracellular transport due to the magnetic dipolar interaction. The formation mechanism of needle-like aggregates inside the endosome is an interesting issue. As yet, we cannot explain this phenomenon. However, this will be our next research goal.

Although the intracellular Fe content was fairly low in the cells cultured on the assemblies, the transmembrane pathway could still be activated. As noted above, the main pathways for the cellular uptake of nanoparticles are clathrin-mediated endocytosis and phagocytosis. The clathrin and the scavenger receptor protein (SR-A) are the typical markers. We detected these two proteins by fluorescent q-polymerase chain reaction (PCR) assay (Fig. $5 \mathrm{a}, \mathrm{b})$. The results reveal that the expression of both clathrin and SR-A decreased with the increase of passage numbers, irrrespective of whether the cells were treated by dissociative nanoparticles or cultured on assemblies of nanoparticles. Moreover, the presence of nanoparticles greatly up-regulated the expression levels of clathrin and SR-A compared with the control. This demonstrates that the signal pathway of cellular uptake was activated by the nanoparticles although the nanoparticles may have been prevented from entering into the cells. Also, the influence on the cells from the dissociative nanoparticles seemed slightly more significant than that from the assembled nanoparticles. Based on Fig. 5, we found the alteration of the clathrin level to be identical in different-passaged cells treated by the dissociative nanoparticles and cultured on 

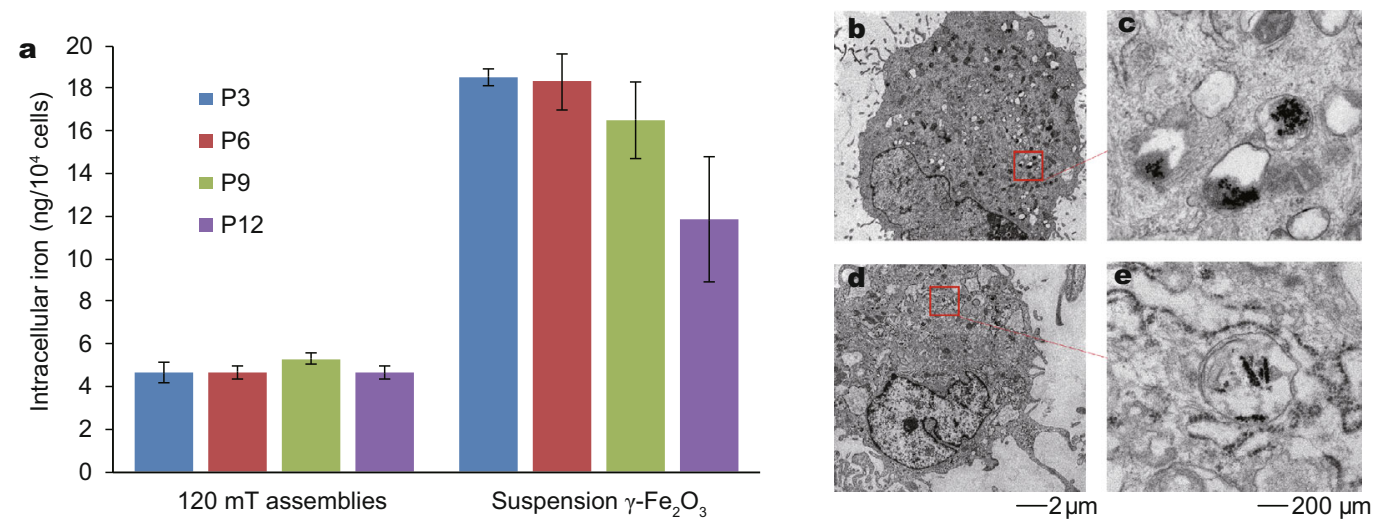

Figure 4 Characterization of cellular uptake for $\gamma-\mathrm{Fe}_{2} \mathrm{O}_{3}$ nanoparticles. (a) Iron concentration measurement by ICP-OES for different-passaged ADSCs treated by the dissociative $\gamma-\mathrm{Fe}_{2} \mathrm{O}_{3}$ nanoparticles and cultured on the stripe-like assemblies, respectively. (b-e) Intracellular localization of $\gamma$ $\mathrm{Fe}_{2} \mathrm{O}_{3}$ nanoparticles characterized by TEM: (b) cells treated by the $\gamma-\mathrm{Fe}_{2} \mathrm{O}_{3}$ nanoparticles and (c) local magnification of (b); (d) cells cultured on the stripe-like assemblies and (e) local magnification of (d).
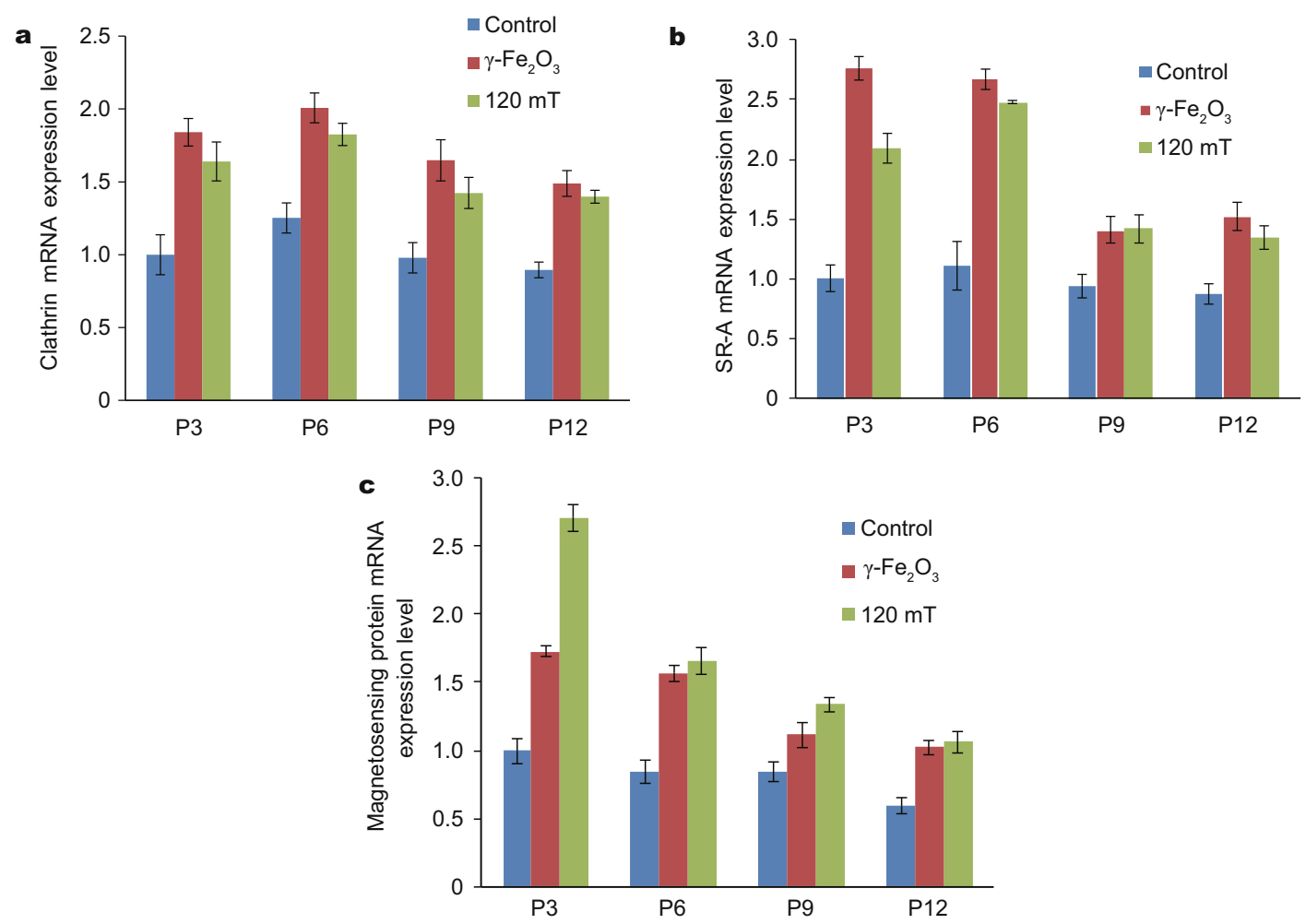

Figure 5 mRNA measurements of clathrin, SR-A protein, and magnetosensing protein for different-passaged ADSCs cultured on cellular culturing plates (control), treated by the dissociative $\gamma-\mathrm{Fe}_{2} \mathrm{O}_{3}$ nanoparticles $\left(\gamma-\mathrm{Fe}_{2} \mathrm{O}_{3}\right)$, and cultured on the stripe-like assemblies (120 mT) with quantitative PCR. (a) mRNA expression level of clathrin. (b) mRNA expression level of SR-A. (c) mRNA expression level of magnetosensing protein.

the assemblies. With the increase of passage numbers, the down-regulation of the clathrin level was less significant. However, the maximal expression of SR-A was at the sixth passage rather than the third and the expression of SR-A protein was significantly down-regulated at the ninth and twelfth passages with respect to the third and sixth passages. This phenomenon can be interpreted with respect to the morphological alteration of the cellular membrane 
because phagocytosis is highly dependent upon the deformation of the cellular membrane. Considering Fig. $4 a$, we hypothesize that both the clathrin-mediated endocytosis and phagocytosis contributed to the entry of nanoparticles into the ADSCs. However, from the viewpoint of the signal pathway, the dominant means of entry for the dissociative nanoparticles was clathrin-mediated endocytosis whereas phagocytosis may play a relatively major role in assembled nanoparticles. Due to the presence of magnetic couplings between the elementary units, cellular phagocytosis was effectively inhibited so that there were only tiny amounts of nanoparticles available to enter into the cells. Thus, the difference in the cellular uptake mechanism between cells treated by dissociative nanoparticles and those cultured on assemblies of nanoparticles may lie in the pathway of cell entry, which results from the different interaction states between individual nanoparticles.

Based on our results, we believe the assembly to have played an important role. The assembly of $\gamma-\mathrm{Fe}_{2} \mathrm{O}_{3}$ nanoparticles reduced the collective free energy of nanoparticles while augmenting the magnetic energy. This hypothesis can be partly supported by our conclusions in previous reports that assemblies of magnetic nanoparticles can mediate the magnetic effect on cells $[13,25]$. Here, we measured the magnetosensing protein by qPCR, which was recently reported to be capable of responding to magnetic interaction (Fig. 5c) [29]. We found that with the increase of passage numbers, the expression of magnetosensing protein was down-regulated and the expression of magnetosensing protein was maximized when the cells were cultured on assemblies of nanoparticles. In addition, the difference in the magnetotsensing protein expression between cells treated by dissociative nanoparticles and those cultured on assemblies of nanoparticles was diminished after the third passage. This result can account for the phenomenon in which the expression level of the SR-A protein became approximately identical in both the cells after the sixth passage. This result also reveals that the magnetic nanoparticles-mediated magnetic effect upon cells grows less effective in senescent cells. Thus, the magnetism-based application of iron oxide nanoparticles may be more suitable for neogenic cells.

\section{CONCLUSIONS}

In conclusion, in this study, we explored for the first time the influence of the number of cellular passages on the uptake of $\gamma-\mathrm{Fe}_{2} \mathrm{O}_{3}$ nanoparticles. We found dissociative nanoparticles to have increasing difficultly in entering adipose-derived stem cells with increasing cellular passages. However, if the nanoparticles are assembled by magnetic field, their cellular uptake can be effectively inhibited, with little difference among the multiple-passaged ADSCs. Our fluorescent q-PCR detection results demonstrated that dissociative and assembled nanoparticles may activate clathrin-mediated endocytosis and phagocytosis, respectively. Here, we believe the assemblymediated magnetic effect plays an important role, which was partly proved by the measurement of the magnetosensing protein. We proposed that the magnetism-based application of iron oxide nanoparticles may be more suitable for neogenic cells. Due to the extremely important role of the cellular uptake of nanoparticles, we believe our work will facilitate the design and protocol development of nanoparticles-based biomedical applications.

Received 21 June 2017; accepted 2 August 2017;

published online 5 September 2017

1 Patel S, Lee KB. Probing stem cell behavior using nanoparticlebased approaches. WIREs Nanomed Nanobiotechnol, 2015, 7: $759-778$

2 Lee IH, Huang SS, Chuang CY, et al. Delayed epidural transplantation of human induced pluripotent stem cell-derived neural progenitors enhances functional recovery after stroke. Sci Rep, 2017, 7: 1943-1955

3 Laar JMV. Immune ablation and stem-cell therapy in autoimmune disease: immunological reconstitution after high-dose immunosuppression and haematopoietic stem-cell transplantation. Arthritis Res, 2000, 2: 270-275

4 Wang X, Li G, Guo J, et al. Hybrid composites of mesenchymal stem cell sheets, hydroxyapatite, and platelet-rich fibrin granules for bone regeneration in a rabbit calvarial critical-size defect model. Exp Ther Med, 2017, 13: 1891-1899

5 Tancharoen W, Aungsuchawan S, Pothacharoen P, et al. Differentiation of mesenchymal stem cells from human amniotic fluid to vascular endothelial cells. Acta Histochemica, 2017, 119: 113-121

6 Tong Y, Niu M, Du Y, et al. Aryl hydrocarbon receptor suppresses the osteogenesis of mesenchymal stem cells in collagen-induced arthritic mice through the inhibition of $\beta$-catenin. Exp Cell Res, 2017, 350: 349-357

7 Tanthaisong $\mathrm{P}$, Imsoonthornruksa S, Ngernsoungnern A, et al. Enhanced chondrogenic differentiation of human umbilical cord Wharton's jelly derived mesenchymal stem cells by GSK-3 inhibitors. PLoS ONE, 2017, 12: e0168059

8 Suzuki A, Saeki T, Ikuji H, et al. Brown algae polyphenol, a prolyl isomerase pin 1 inhibitor, prevents obesity by inhibiting the differentiation of stem cells into adipocytes. PLoS ONE, 2016, 11: e0168830

9 Boquest AC, Shahdadfar A, Brinchmann JE. Isolation of stromal stem cells from human adipose tissue. Methods Mol Biol, 2006, 325: 35-46

10 Lindroos B, Suuronen R, Miettinen S. The potential of adipose stem cells in regenerative medicine. Stem Cell Rev Rep, 2011, 7: 
269-291

11 Geburek F, Roggel F, van Schie HTM, et al. Effect of single intralesional treatment of surgically induced equine superficial digital flexor tendon core lesions with adipose-derived mesenchymal stromal cells: a controlled experimental trial. Stem Cell Res Ther, 2017, 8: 129

12 Hadavi M, Hasannia S, Faghihi S, et al. Novel calcified gum Arabic porous nano-composite scaffold for bone tissue regeneration. Biochem Biophys Res Commun, 2017, 488: 671-678

13 Liu X, Zhang J, Tang S, et al. Growth enhancing effect of LBLassembled magnetic nanoparticles on primary bone marrow cells. Sci China Mater, 2016, 59: 901-910

14 Ngadiman NHA, Idris A, Irfan $\mathrm{M}$, et al. $\gamma-\mathrm{Fe}_{2} \mathrm{O}_{3}$ nanoparticles filled polyvinyl alcohol as potential biomaterial for tissue engineering scaffold. J Mech Behav Biomed Mater, 2015, 49: 90-104

15 Lu L, Unsworth LD. pH-Triggered release of hydrophobic molecules from self-assembling hybrid nanoscaffolds. Biomacromolecules, 2016, 17: 1425-1436

16 Verma A, Uzun O, Hu Y, et al. Surface-structure-regulated cellmembrane penetration by monolayer-protected nanoparticles. Nat Mater, 2008, 7: 588-595

$17 \mathrm{Gu} J \mathrm{~L}, \mathrm{Xu} \mathrm{HF}$, Han YH, et al. The internalization pathway, metabolic fate and biological effect of superparamagnetic iron oxide nanoparticles in the macrophage-like RAW264.7 cell. Sci China Life Sci, 2011, 54: 793-805

18 Sahay G, Alakhova DY, Kabanov AV. Endocytosis of nanomedicines. J Control Release, 2010, 145: 182-195

19 Conner SD, Schmid SL. Regulated portals of entry into the cell. Nature, 2003, 422: 37-44

20 Zhao P, Cao M, Song L, et al. Downregulation of MIM protein inhibits the cellular endocytosis process of magnetic nanoparticles in macrophages. RSC Adv, 2016, 6: 96635-96643

21 da Luz CM, Boyles MSP, Falagan-Lotsch P, et al. Poly-lactic acid nanoparticles (PLA-NP) promote physiological modifications in lung epithelial cells and are internalized by clathrin-coated pits and lipid rafts. J Nanobiotechnol, 2017, 15: 11-29

22 Banerjee A, Berezhkovskii A, Nossal R. Kinetics of cellular uptake of viruses and nanoparticles via clathrin-mediated endocytosis. Phys Biol, 2016, 13: 016005

23 Scheinpflug DK. Measurement of cell membrane fluidity by laur- dan GP: fluorescence spectroscopy and microscopy. Methods Mol Biol, 2017, 1520: 159-174

24 Wang Q, Chen B, Cao M, et al. Response of MAPK pathway to iron oxide nanoparticles in vitro treatment promotes osteogenic differentiation of hBMSCs. Biomaterials, 2016, 86: 11-20

25 Sun J, Liu X, Huang J, et al. Magnetic assembly-mediated enhancement of differentiation of mouse bone marrow cells cultured on magnetic colloidal assemblies. Sci Rep, 2015, 4: 5125

26 Chamberlain G, Fox J, Ashton B, et al. Concise review: mesenchymal stem cells: their phenotype, differentiation capacity, immunological features, and potential for homing. Stem Cells, 2007, 25: $2739-2749$

27 Sufian MM, Khattak JZK, Yousaf S, et al. Safety issues associated with the use of nanoparticles in human body. Photodiagnosis Photodynamic Ther, 2017, 19: 67-72

28 Decuzzi P, Ferrari M. The receptor-mediated endocytosis of nonspherical particles. BioPhys J, 2008, 94: 3790-3797

29 Qin S, Yin H, Yang C, et al. A magnetic protein biocompass. Nat Mater, 2015, 15: 217-226

Acknowledgements This work was supported by the National Basic Research Program of China (2013CB733801) and the National Key Research and Development Program of China (2017YFA0104301). Sun J is thankful to the supports from the Fundamental Research Funds for the Central Universities. All authors are thankful to the supports from Collaborative Innovation Center of Suzhou Nano Science and Technology.

Author contributions Sun J designed the experiments, analyzed the results and modified the manuscript. Yang Y did all the experiments with the help of Wang Q and Zhao P and wrote the manuscript with the help from Sun J and Liu X. Song L provided the nanoparticle solution. $\mathrm{Gu} \mathrm{N}$ and Zhang F supervised the project. All authors contributed to the general discussion.

Conflict of interest The authors declare that they have no conflict of interest.

Supplementary information Supprting data are available in the online version of the paper. 


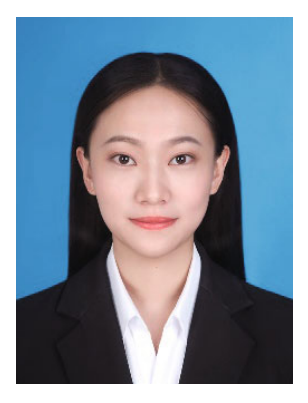

Yan Yang received her BSc degree in biotechnology from Anhui University in 2014. Now she is pursuing her master degree in biomedical engineering at Southeast University. His research interest is the assembly of nanoparticles.

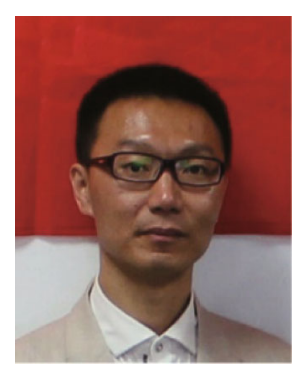

Jianfei Sun received his $\mathrm{PhD}$ degree in biomedical engineering from Southeast University in 2008. He is now an associate professor at the School of Biological Science and Medical Engineering, Southeast University. His research interests include the fabrication of nanoelectronic devices by self-assembly of nanoparticles and their application in biomedical issues.

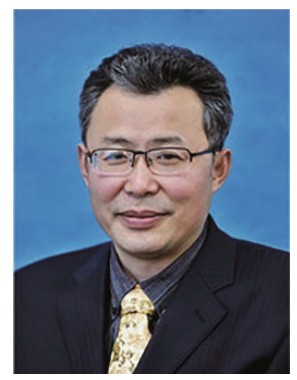

Ning Gu received his $\mathrm{PhD}$ degree in biomedical engineering from the Department of Biomedical Engineering,Southeast University, Nanjing, China, in 1996. Currently he is a Cheung Kong Scholar Chair Professor at the School of Biological Science and Medical Engineering, Southeast University and Director of Jiangsu Key Laboratory of Biomaterials and Devices. His research interests include the applications of magnetic nanomaterials in biomedicine.

\section{不同传代数对脂肪间充质干细胞摄取磁性纳米颗粒的影响研究}

杨燕, 王琪炜 ${ }^{1}$, 宋丽娜 ${ }^{1}$, 刘璇 ${ }^{2}$, 赵鹏 ${ }^{1}$, 章非敏 ${ }^{3}$, 顾宁 ${ }^{1^{*}}$, 孙剑飞 ${ }^{1 *}$

摘要 随着纳米材料在组织工程和再生医学中越来越多的应用, 干细胞和纳米材料之间的相互作用成为关键环节, 而纳米颗粒进入细胞 是关系到纳米材料安全性和干细胞命运调控的首要问题. 干细胞传代是其应用中必不可少的过程, 但关于传代代数对干细胞摄取纳米颗 粒的影响的研究还较少. 此外, 干细胞和纳米材料的相互作用还与纳米颗粒的存在方式有关. 本文在玻璃片上组装了条带状的 $\gamma-\mathrm{Fe}_{2} \mathrm{O}_{3}$ 纳米 颗粒组装结构, 并在该表面上培养SD大鼠脂肪间充质干细胞, 然后研究了不同代数的干细胞对组装和游离的纳米颗粒的吞噬情况. 结果发 现, 随着细胞代数增加, 细胞活力降低, 细胞衰老水平增加, 并且细胞膜的表面呈现出粗粘和不均匀的形貌. 当与游离的 $\gamma-\mathrm{Fe}_{2} \mathrm{O}_{3}$ 纳米颗粒共 培养时, 细胞内铁含量随着代数的增加而减少, 但在组装体上培养的不同代数的细胞具有相似的铁含量, 并且胞内铁含量极少. 另外, 磁感 应蛋白的表达表明磁性纳米颗粒的组装体对细胞有磁效应. 该研究表明, 细胞代数的选择对研究颗粒内化实验是至关重要的, 细胞代数应 该作为细胞摄取实验的一个重要考虑因素. 